\title{
0 uso de jogos digitais no desenvolvimento da consciência fonológica no processo de alfabetização: intervenções no contexto escolar
}

\author{
Luciana Augusta Ribeiro do Prado ${ }^{1}$ (D) ; Daniela Karine Ramos ${ }^{1}$ \\ ${ }^{1}$ Universidade Federal de Santa Catarina (UFSC), Brasil
}

Resumo. Este estudo tem o objetivo de avaliar as contribuições do uso de jogos digitais para o desenvolvimento da consciência fonológica junto a crianças com dificuldades no processo de alfabetização na escola. A metodologia de pesquisa utilizada foi quase-experimental com abordagens quantitativa e qualitativa. Participaram dessa pesquisa 14 estudantes com dificuldades escolares, matriculados no terceiro e quarto ano do Ensino Fundamental de duas escolas públicas do município de Florianópolis no sul do Brasil. A coleta de dados ocorreu por meio da aplicação de testes - Teste de desempenho escolar (TDE) e Consciência Fonológica: Instrumento de Avaliação Sequencial (CONFIAS), da realização de entrevista com as professoras e do registro de observação. A intervenção ocorreu no período de dois meses, com total 12 horas. Os estudantes foram acompanhados por meio do protocolo de observação participante que registrou seus comportamentos durante a intervenção. As informações coletadas foram organizadas e sistematizadas, demonstraram que o uso dos jogos digitais na escola contribuiu no processo de alfabetização dos estudantes. Conclui-se que uso dos jogos digitais proporcionam uma experiência significativa para o processo de alfabetização no contexto escolar.

Palavras-chave: jogos digitais; alfabetização; consciência fonológica; contexto escolar.

El uso de juegos digitales en el desarrollo de la conciencia fonológica en el proceso de alfabetización: intervenciones en el contexto escolar

Resumen. Este estudio tiene el objetivo de evaluar las aportaciones del uso de juegos digitales al desarrollo de la conciencia fonológica de niños y niñas con dificultades en el proceso de alfabetización escolar. Se ha utilizado una metodología de investigación cuasiexperimental, con enfoques cuantitativos y cualitativos. Participaron en esta investigación catorce (14) estudiantes con dificultades de aprendizaje, matriculados en el tercer y cuarto curso de la educación primaria de dos escuelas públicas de la ciudad de Florianópolis, en el sur de Brasil. La recogida de datos se llevó a cabo mediante la aplicación de pruebas -Test de Rendimiento Escolar (TRES) y Conciencia Fonológica: Instrumento de Evaluación Secuencial (CONFIAS), entrevista con las maestras y registro de observación. La intervención tuvo lugar a lo largo de dos meses, con un total de 12 horas. Se hizo el seguimiento de los estudiantes por medio del protocolo de observación de los participantes, en el que se registró su comportamiento durante la intervención. La información recogida se organizó y se sistematizó, demostrando que el uso de juegos digitales en la escuela ha contribuido al proceso de alfabetización de los estudiantes. Se concluye que el uso de juegos digitales proporciona una experiencia relevante para el proceso de alfabetización en el contexto escolar.

Palabras clave: juegos digitales; alfabetización; conciencia fonológica; contexto escolar.

The use of digital games in the development of phonological awareness in the literacy process: interventions in the school context

Abstract: This study aims to evaluate the contributions of the use of digital games for the development of phonological awareness of children with difficulties in the process of literacy. The research methodology used was quasi-experimental with quantitative and qualitative approaches. Participated in this research 14 students with school difficulties in the third and fourth year of the elementary school in two public schools in the city of Florianópolis, Brazil's South Region. Data collection occurred through the application of the tests - School Performance Test (TDE) and Phonological Awareness: Sequential Assessment Instrument (CONFIAS), conducting interviews with teachers, and observation notes. The intervention took place over a period of two months, with a total of 12 hours. The students were followed up using the participant observation protocol that noted their behavior during the intervention. The information collected was organized and systematized, showing that the use of digital games at school contributed to the students' literacy process. It is concluded that the use of digital games provides a significant experience for the process of literacy in the school context.

Keywords: digital games; literacy; phonological awareness; school context. 


\section{Introdução}

A área da educação lida com desafios continuamente e busca estratégias para aprimorar os processos de ensino e aprendizagem. Sobretudo, em relação ao processo de alfabetização dos estudantes das escolas brasileiras que enfrentam problemas, especialmente relacionados ao domínio adequado das habilidades de leitura e escrita nos anos iniciais da educação básica. Conforme o relatório Indicador de Anafalbemo Funcional - 2018 (Inaf - 2018), constata-se que 34\% dos estudantes que concluíram o Ensino Fundamental, não conseguem ler um bilhete simples por não ser proficiente em leitura e escrita (Instituto Paulo Montenegro, 2018). Esse relatório buscou as informações com uma porção proporcional à população brasileira. Sua totalidade são pessoas, escolhidas por sorteio, com idade entre $15 \mathrm{e}$ 64 anos, residentes nas regiões urbanas e rurais do Brasil. A alfabetização é um processo complexo que envolve diversos aspectos, desde linguíticos, interativos e sociais, sendo que esses dois últimos envolvem os usos sociais da língua escrita (Soares, 2017).

Neste artigo aborda-se o aspecto linguístico da consciência fonológica no processo de alfabetização (Adams, Foorman, Lundberg \& Beeler, 2006; Lamprecht, 2009). Porque é premente a demanda por recursos pedagógicos, principalmente, ao que se refere a alternativas lúdicas, no sentido de atrair a atenção dos estudantes para mobilizá-los para a aprendizagem e oferecer diversificadas estratégias para atender as diferentes condições de aprendizagem e realidades vividas pelas crianças em processo de alfabetização.

Dentre os inúmeros recursos pedagógicos, destacam-se os jogos digitais para o desenvolvimento da consciência fonológica no processo de alfabetização, como alternativas efetivas para contribuir na aprendizagem do sistema de escrita alfabética (Kulju \& Mäkinen, 2019; Jamshidifarsani, Garbaya, Lim, Blazevic \& Ritchie, 2019; Ronimus, Kujala, Tolvanen \& Lyytinen, 2014; Rosas, Escobar, Ramírez, Meneses \& Guajardo, 2017; Richardson \& Lyytinen, 2014).

A consciência fonológica consiste na atividade metalinguística de refletir sobre a língua, analisar os sons da fala e manipulá-los, englobando a consciência das sílabas, rimas, aliterações, unidades intrassilábicas e fonemas (Adams et al., 2006; Capovilla \& Capovilla, 2002; Maluf \& Barrera, 1997; Moojen, 2011). 
Algumas pesquisas sobre alfabetização defendem que os professores que trabalham o desenvolvimento da consciência fonológica promovem um avanço mais efetivo em leitura e escrita, portanto contribuem para o aprendizado da turma como um todo e reduzem o fracasso no processo de alfabetização (Capovilla \& Capovilla, 2002; Maluf \& Barrera, 1997).

Destaca-se que o uso de jogos digitais na prática educativa pode ser uma alternativa para trabalhar a consciência fonológica. Entretanto, cabe avaliar e refletir sobre as suas contribuições ao processo de aprendizagem dos estudantes. Inclusive em relação à inclusão digital por meio dos jogos digitais, com o emprego das Tecnologias de Informação e Comunicação (TIC) possibilitam condições de aprendizagem e letramento digital (Ramos, Melo \& Mattar, 2018). Constata-se que as TIC influenciaram a sociedade em diversos âmbitos, tanto econômicos como culturais, transformaram as formas de pensar, agir e comunicar (Pérez-Gómez, 2015). Reflete na forma de aquisição e compartilhamento de conhecimentos e as formas de aprendizado da leitura e escrita.

Pesquisadores e educadores procuram fundamentar seus estudos em evidências, tanto com bases estudos quase-experimentais de abordagem quantitativas, como em abordagens mais qualitativas para compreender como o jogo, enquanto um artefato cultural, que pode contribuir para o processo de ensino e aprendizagem (Alves \& Coutinho, 2016).

Os jogos possuem quatro características definidoras "meta, regras, sistema de feedback e participação voluntária" (Mcgonigal, 2012, p. 30). Entretanto, os jogos digitais possuem outras características que os complementam como "interatividade, gráficos, narrativa, recompensas, competitividade, ambientes virtuais" (Mcgonigal, 2012, p. 31). Esses elementos dos jogos digitais atrelados aos demais recursos, potencializam a jogabilidade, por ser um sistema complexo que automatiza as informações no meio digital, contribui para um feedback imediato em tempo real e interativo, tanto com o ambiente do jogo, quanto com a interação junto a outros jogadores (Salen \& Zimmerman, 2012).

Em relação aos níveis de consciência fonológica, quanto mais o jogo digital possuir elementos que automatizem os dados com as informações, como por exemplo, jogos que apresentam a representação fonológica (Morais, 2013) com a emissão dos sons, uso de gráficos e animações, atrelados aos efeitos sonoros (Boler \& Kapp, 2018) para representar as palavras, sílabas ou os fonemas (Adams et al., 2006; Lamprecht, 2009), tornam dinâmica e atrativa a aprendizagem dos níveis de consciência fonológica. 
Estudo revela evidências que os jogos digitais contribuem com o processo de alfabetização, constatando melhor rendimento no processo de leitura de palavras e pseudo-palavras. A maioria desses jogos desenvolvem a consciência fonêmica, alguns utilizam o método fônico, principalmente para os estudantes que passam por dificuldades de aprendizagem e dislexia (Kulju \& Mäkinen, 2019; Jamshidifarsani et al., 2019; Ronimus et al., 2014; Rosas et al., 2017; Richardson \& Lyytinen, 2014).

A partir disso, a problemática norteadora deste trabalho é: De que forma os jogos digitais voltado para o desenvolvimento da consciência fonológica podem contribuir no processo de alfabetização? Nesse sentido, a justificativa para essa problemática está na necessidade de encontrar estratégias e métodos para alfabetizar os estudantes de forma efetiva. Esses aspectos remetem a necessidade de ampliar a compreensão compreender sobre como o emprego desses recursos podem impactar no aprendizado dos estudantes no ambiente escolar. Diante disso, este estudo tem o objetivo de avaliar as contribuições do uso de jogos digitais para o desenvolvimento da consciência fonológica junto a crianças com dificuldades no processo de alfabetização na escola.

\section{Metodologia de pesquisa}

A pesquisa desenvolvida caracteriza-se como quase-experimental, utilizando uma abordagem mista, por meio da comparação do grupo experimental e controle (Creswell, 2007; Gil, 2002). O campo de pesquisa foram duas escolas públicas do município de Florianópolis no sul do Brasil.

Os participantes foram 14 estudantes com dificuldades no processo de alfabetização que eram atendidos no serviço de apoio pedagógico. Este serviço tem como objetivo oferecer oportunidades de aprendizagem e ampliar o tempo na escola. Os estudantes estavam matriculados no $3^{\circ}$ e $4^{\circ}$ ano do Ensino Fundamental, com idades entre 8 e 11 anos. Todos tiveram a permissão dos pais ou responsáveis, por meio da assinatura do Termo de Consentimento Livre e Esclarecido.

A amostra foi composta por conveniência e a composição dos grupos observou a sua estratificação considerando a idade e ano escolar. Os critérios para seleção dos participantes foram: participar dos atendimentos do serviço de apoio pedagógico; ter dificuldades no processo de alfabetização; estar matriculado nos $3^{\circ}$ ou $4^{\circ}$ ano. Os participantes selecionados foram distribuídos em dois grupos, um experimental (GE) que participou da intervenção composto por 7 estudantes da uma escola, e o grupo controle (GC) com 7 estudantes 
de outra escola, que não participaram da intervenção (Creswell, 2007; Gil, 2002). A definição do grupo experimental considerou a disponibilidade dos dispositivos para o acesso aos jogos digitais da escola participante.

A coleta quantitativa ocorreu por meio da aplicação de testes antes e após o período da intervenção. Os testes utilizados foram:

a) Teste de desempenho escolar - TDE: é um instrumento psicométrico que avalia as capacidades fundamentais para o desempenho escolar que emblobam a escrita, leitura e a aritmética. Os testes utilizados nessa pesquisa foram os subtestes de escrita e leitura. Sendo que o subteste de escrita foi avaliado de duas formas quantitativa e qualitativa. A primeira forma, verifica o número de palavras corretas e a segunda, identifica o tipo de incorreção realizada pelo estudante (Stein, 2014).

b) Consciência Fonológica - Instrumento de Avaliação Sequencial - CONFIAS: é utilizado para diagnosticar o nível de consciência fonológica dos estudantes. 0 instrumento está dividido em duas partes que envolvem a consciência silábica e a fonêmica. A avaliação considera as relações com as hipóteses da escritas (Ferreiro \& Teberosky, 1999) pré-silábica, silábica, silábicoalfabética e alfabética (Moojen, 2011).

Além desses instrumentos, a coleta ocorreu também por meio entrevistas com as professoras para registrar sua avaliação e percepção em relação à aprendizagem do estudante, e quanto seu processo de alfabetização no período da pesquisa (Creswell, 2007; Gil, 2002). As entrevistas foram estruturadas em relação as habilidades desenvolvidas pelo estudante, considerando os seguintes aspectos:

1. distinção dos sinais do sistema de escrita alfabético ortográfico de outros símbolos e outras formas de representação gráfica;

2. conhecimento do alfabeto e os diferentes tipos de letras;

3. orientação na escrita, escrevendo da esquerda para direita e observação quanto aos espaços entre as palavras na escrita da frase;

4. identificação das rimas e aliterações;

5. associação letra ao som, reconhece e associa a sílaba ao som;

6. compreensão das relações entre grafemas e fonemas, sobretudo aquelas relações que são regulares; 
7. leitura e compreensão das palavras compostas por sílabas canônicas (consoante + vogal);

8. Ieitura e compreensão de frases com estrutura simples; compreensão global um texto lido pelo(a) professor(a), identificando 0 assunto principal;

9. Ieitura com fluência;

10. escrita de palavras familiares e memorizadas;

11. produção textual.

As professoras participantes que atuavam nas séries iniciais ( 5 professoras) e no apoio pedagógico ( 2 professoras), foram convidadas a avaliar as habilidades dos estudantes na entrevista, indicando um nível de capacidade: capacidades ainda não desenvolvidas; capacidades em desenvolvimento (domínio parcial ou transição de níveis) ou capacidades já desenvolvidas (Batista, Silva, Bregunci, Castanheira \& Monteiro, 2008). Além disso, os professores descreveram aspectos observados nas crianças relacionados ao processo de alfabetização.

As respostas das entrevistas foram tabuladas e contabilizadas, considerando as percepções quantitativas e qualitativas. Assim, o processo de pesquisa foi fundamentado com a validade e a confiabilidade na coleta e análise das informações (Merriam \& Tisdell, 2016).

Os procedimentos de coleta incluíram o acompanhamento das intervenções por meio de um "Protocolo de Observação participante", para participação direta da pesquisadora para registrar a observação em grupo e individual (Lüdcke \& André, 1986). Em cada dia de intervenção, a observação do grupo ocorreu com o registro de comportamentos por uma relação de questões a serem verificadas, a partir da escala Likert (nunca, raramente, às vezes, muitas vezes, sempre): 1 . Os estudantes demonstraram envolvidos no jogo que perderam a noção do tempo? 2. Os estudantes sorriram e comemoravam ao jogar? 3. Os estudantes pediram para trocar de jogo ou terminar a atividade? 4. Manifestaram comportamentos competitivos como por exemplo, comparar a pontuação? 5. Os estudantes prestaram auxílio aos colegas? 6. Os estudantes entenderam o jogo. 7. Os estudantes jogaram com autonomia. 8. Os estudantes avançam as etapas do jogo? 9. Os estudantes vencem progressivamente os desafios.

Na observação individual registrou três comportamentos, em cada dia de intervenção: 1 . 0 estudante apresenta um bom desempenho relacionado com a consciência fonológica. 2 . Houve a necessidade de dar atenção especial ao estudante. 3. 0 estudante apresentou dificuldades para entender o jogo. 
Nessa observação individual das crianças registrou-se os comportamentos em relação ao desempenho da consciência fonológica no jogo, a necessidade de mediação na interação com o jogo digital e as dificuldades. Esses comportamentos foram registrados em cada sessão a partir de uma lista de verificação (Bentzen, 2013), onde se marcou sim ou não para identificar a presença ou ausência do comportamento. A partir disso, forma contabilizados o percentual em relação ao total de "sim".

A intervenções ocorreram com o emprego dos jogos digitais para o desenvolvimento da consciência fonológica. Esses jogos foram selecionados para atender os objetivos de aprendizagem previstos nas intervenções que incluíam o exercício dos jogos de linguagem, a reflexão sobre a língua, a manipulação e análise dos sons da fala. 0 desenvolvimento das habilidades de consciência fonológica é um processo continuum, desde a consciência da palavra, até a consciência do fonema para contribuição com o processo de alfabetização (Adams et al., 2006; Lamprecht, 2009).

Além disso, os jogos digitais, tanto em desktop como e Android, deveriam estar disponíveis de forma gratuita e precisavam funcionar adequadamente nos computadores e tablets disponíveis na escola participante.

Os jogos selecionados para a intervenção foram em plataformas móveis: Domlexia; Lelê sílabas; Silabando; Formar palavras; Palma escola; Jogo 3 Letras. Para plataformas desktop foram: Primeira letra da palavra; Quantos pedaços tem a palavra; Duelo de palavras; Sílabas e Figuras; Encaixa vogais; Encontre as rimas.

A partir da seleção dos jogos digitais procedeu-se ao planejamento das intervenções que realizadas no segundo semestre de 2019. O GE foi o grupo ativo que passou pelas intervenções com os jogos digitais de consciência fonológica, durante 8 semanas, 2 vezes por semana, contabilizando 16 sessões de 45 minutos cada e totalizando 12 horas de intervenção na escola.

Para análise dos dados as informações foram organizadas e tabuladas, posteriormente foram analisados no software SPSS (Statistical Package for the Social Sciences) versão 24 para análise estatística. Foram utilizados testes estatísticos não paramétricos, devido a amostra ser pequena. Para comparar duas amostras independentes em relação às medianas, foi utilizado o teste $U$ Mann-Whitney (Dancey \& Reidy, 2019). Considerou-se na análise o tamanho do efeito, pelo método do coeficiente d de Cohen, tomando como referência que $(d=0,2)$ é um efeito pequeno, $(d=0,5)$ um efeito médio e $(d=0,8)$ um efeito grande (Espiríto Santo \& Daniel, 2017). 
A pesquisa foi autorizada, segundo o parecer $n .^{\circ} 3.437 .469$, seguiu as orientações do Comitê de Ética da (Blind Review - Universidade Federal de Santa Catarina - UFSC), quanto as metodologias próprias das áreas de Ciências Humanas e Sociais, sobre as questões éticas relacionadas à pesquisa para benéfico para toda a sociedade.

\section{Resultados}

No decorrer das intervenções realizadas observou-se a interação das crianças com os jogos digitais para o desenvolvimento da consciência fonológica para promover o aprendizado dos estudantes, por meio do "Protocolo de observação participante". A partir desses registros sistematizou-se a frequência que alguns comportamentos relacionados ao interesse, a competição, ao envolvimento nas intervenções, a autonomia e a superação dos desafios. Na Tabela 1 são sistematizados os resultados obtidos.

Tabela 1. Observação do grupo de estudantes nas intervenções com os jogos

Comportamentos Registros

1. Os estudantes demonstraram 50\% (sempre), $43 \%$ (muitas vezes), $3 \%$ (às vezes), $3 \%$ envolvidos no jogo que perderam a (raramente), $0 \%$ (nunca).

noção do tempo?

2. Os estudantes sorriram e comemoravam ao jogar?

$46 \%$ (sempre), $50 \%$ (muitas vezes), $3 \%$ (às vezes), $0 \%$ (raramente), 0\% (nunca).

3. Os estudantes pediram para trocar 3\% (sempre), $6 \%$ (muitas vezes), $18 \%$ (às vezes), $21 \%$ de jogo ou terminar a atividade? (raramente), 50\% (nunca).

4. Manifestaram comportamentos 13\% (sempre), 3\% (muitas vezes), 13\% (às vezes), competitivos como por exemplo, 21\% (raramente), 50\% (nunca). comparar a pontuação?

5. Os estudantes prestaram auxílio 37\% (sempre), 18\% (muitas vezes), $28 \%$ (às vezes), aos colegas? 3\% (raramente), 4\% (nunca).

6. Os estudantes entenderam o jogo. $46 \%$ (sempre), $50 \%$ (muitas vezes), $3 \%$ (às vezes), $0 \%$ (raramente), 0\% (nunca).

7. Os estudantes jogaram com au- 21\% (sempre), $56 \%$ (muitas vezes), $21 \%$ (às vezes), tonomia.

$0 \%$ (raramente), 0\% (nunca).

8. Os estudantes avançam as etapas $21 \%$ (sempre), $71 \%$ (muitas vezes), $6 \%$ (às vezes), $0 \%$ do jogo? (raramente), 0\% (nunca).

9. Os estudantes vencem progressi- $31 \%$ (sempre), $65 \%$ (muitas vezes), $3 \%$ (às vezes), $0 \%$ vamente os desafios. (raramente), 0\% (nunca).

Fonte: Elaboração própia.

A partir dos registros de observação percebe-se que há envolvimento dos estudantes com o jogo, que eles se divertiam e não eram muito competitivos, bem como conseguiam entender o jogo e tinham certa autonomia para jogar. 
Já a observação individual, requereu certa atenção para acompanhar as ausências, e inclusive, em relação ao desempenho individual de cada estudante. Houve o acompanhamento, em relação ao aprendizado de cada um quanto à consciência fonológica no processo de alfabetização. Isso foi possível devido ao protocolo de observação com lista de verificação (Bentzen, 2013), como instrumento de coleta, e o grupo com número reduzido de participantes, total de 7 no grupo experimental.

Tabela 2. Observação individual dos estudantes nas intervenções com os jogos

\begin{tabular}{lcccc} 
& Comportamento & Comportamento & Comportamento & Ausências \\
& 1 & 2 & 3 & \\
\hline Estudante 1 & $100 \%$ & $25 \%$ & $25 \%$ & 0 \\
Estudante 2 & $81,25 \%$ & $18,75 \%$ & $12,50 \%$ & 3 \\
Estudante 3 & $75 \%$ & $6,50 \%$ & $0,00 \%$ & 3 \\
Estudante 4 & $75 \%$ & $12,50 \%$ & $6,50 \%$ & 2 \\
Estudante 5 & $62,50 \%$ & $0 \%$ & $0 \%$ & 10 \\
Estudante 6 & $56,25 \%$ & $12,50 \%$ & $12,50 \%$ & 5 \\
Estudante 7 & $37,50 \%$ & $81,25 \%$ & $68,75 \%$ & 6
\end{tabular}

Notas. Comportamento $1=0$ estudante apresenta um bom desempenho relacionado com a consciência fonológica; Comportamento 2 = Ocorre a necessidade de dar atenção especial ao estudante; Comportamento 3 = 0 estudante apresenta dificuldades para entender o jogo. Fonte: Elaboração própia.

Observa-se que o estudante 1 teve um bom desenvolvimento relacionado à consciência fonológica, não teve ausência nas intervenções, ao mesmo tempo que não exigiu atenção constante, somente nos primeiros dias relacionados ao uso do computador e do tablet. 0 estudante 7 , foi 0 que mais apresentou dificuldades em relação à compreensão da consciência fonológica, requereu mais atenção da pesquisadora e apresentou dificuldades ao entender o jogo. Já o estudante 5 , não necessitou de ajuda da pesquisadora, e entendeu o jogo bem, mas em relação à consciência fonológica as informações coletadas com o instrumento foram escassas devido o número alto de ausências nas intervenções.

Os resultados relacionados ao desenvolvimento da consciência fonológica e a aprendizagem do sistema de escrita alfabética, foi avaliado por meio da aplicação dos testes com os estudantes e das entrevistas com as professoras, que possibilitou analisar suas percepções em relação ao uso dos jogos digitais. 
A primeira análise ocorreu por meio do teste $t$, considerando que os dados seguiam uma distribuição normal, para maior validade da pesquisa em relação às avaliações pré teste que incluiu a aplicação dos instrumentos do TDE II - Escrita, TDE II - Leitura, CONFIAS. Essa análise buscou verificar se os grupos não apresentavam diferenças significativas em relação ao desempenho nos testes, conforme a Tabela 3.

Tabela 3. Resultado das médias do teste t de student para amostras pareadas nos escores dos testes pré intervenção TDE II - Escrita, TDE II - Leitura e CONFIAS

\begin{tabular}{lllll}
\hline & \multicolumn{1}{c}{$\begin{array}{c}\text { Média } \\
\text { Grupo } \begin{array}{c}\text { Experimental } \\
\text { (DP) }\end{array}\end{array}$} & $\begin{array}{c}\text { Média } \\
\text { Grupo Controle } \\
\text { (DP) }\end{array}$ & $t$ & $p$ \\
\hline TDE II - Escrita - Pré & $5,85(2,02)$ & $8,14(3,56)$ & $-0,557$ & 0,4 \\
TDE II - Leitura - Pré & $14,42(5,25)$ & $12,00(5,44)$ & 0,321 & 0,872 \\
CONFIAS - Pré & $40,28(2,94)$ & $36,28(3,64)$ & 0,853 & 0,698
\end{tabular}

Nota: (DP) Desvio Padrão; $p<0,005$.

Fonte: Elaboração própia.

Na tabela 3, observamos que a comparação das médias das variáveis dependentes resultantes do desempenho nas avaliações pode ser considerada simétrica, pois não se observa uma diferença estatisticamente significativa. O GE e o GC possuem médias aproximadas. O desvio padrão não apresenta grande dispersão em torno da média e são equivalentes em relação aos grupos. Esse resultado reforça a validade entre os grupos nesse estudo (Dancey \& Reidy, 2019).

Os resultados dos testes aplicados nos dois grupos são apresentados na Tabela 4, incluindo a diferença entre o pré e pós teste.

Constata-se que as intervenções com os jogos digitais para o desenvolvimento da consciência fonológica para a alfabetização, contribuem no processo de aprendizagem do sistema de escrita alfabética. Destaca-se o TDE II - Leitura, no GE com 9 pontos de diferença nas medianas em relação ao GC.

Desse modo, ressalta-se que a intervenção com os jogos digitais de consciência fonológica para a alfabetização promove algum efeito no processo de aprendizagem dos estudantes, devido aos escores apresentarem uma diferença na mediana significativa, entre 9 pontos nos escores no teste de leitura entre o grupo experimental e controle. A significância estatística foi demonstrada, devido a maioria dos valores ser menor que 0,05 , com exceção a entrevista da professora de anos iniciais que apresentou significância de $(p=0,073)$. Observa-se, ainda, que a avaliação do CONFIAS, quase atinge uma significância estatística, pois apresentou $(p=0,053)$. 
Tabela 4. Comparação da diferença mediana nos testes pré e pós entre o grupo experimental e controle

\begin{tabular}{|c|c|c|c|c|c|c|c|c|}
\hline & \multicolumn{2}{|c|}{ Experimental } & \multicolumn{2}{|c|}{ Controle } & \multirow[b]{2}{*}{$\begin{array}{c}\text { U de Mann } \\
\text { Whitney }\end{array}$} & \multirow[b]{2}{*}{$p$} & \multirow[b]{2}{*}{$d$} & \multirow[b]{2}{*}{$\begin{array}{l}\text { Tamanho } \\
\text { do } \\
\text { Effect }(r)\end{array}$} \\
\hline & Mediana & $\begin{array}{l}\text { Amplitude } \\
\text { interquartil }\end{array}$ & Mediana & $\begin{array}{l}\text { Amplitude } \\
\text { interquartil }\end{array}$ & & & & \\
\hline TDE-E-pré & 7,00 & 11,00 & 6,00 & 13,00 & & & & \\
\hline TDE-E-pós & 12,00 & 12,00 & 6,00 & 8,00 & 5,00 & $0,011^{*}$ & & \\
\hline Diferença & 4,00 & 2,00 & 0,00 & 2,00 & & & 0,42 & 0,20 \\
\hline TDE-L-pré & 16,00 & 27,00 & 5,00 & 28,00 & & & & \\
\hline TDE-L-pós & 29,00 & 23,00 & 15,00 & 28,00 & 7,00 & $0,026^{*}$ & & \\
\hline Diferença & 11,00 & 9,00 & 2,00 & 4,00 & & & 0,35 & 0,17 \\
\hline CONFIAS-pré & 43,00 & 14,00 & 33,00 & 13,00 & & & & \\
\hline CONFIAS-pós & 56,00 & 13,00 & 41,00 & 21,00 & 9,00 & 0,053 & & \\
\hline Diferença & 13,00 & 4,00 & 8,00 & 7,00 & & & 0,32 & 0,16 \\
\hline Professora-pré & 28,00 & 14,00 & 23,00 & 2,00 & & & & \\
\hline Professora-pós & 32,00 & 17,00 & 32,00 & 8,00 & 38,50 & 0,073 & & \\
\hline Diferença & 3,00 & 4,00 & 8,00 & 7,00 & & & $-0,28$ & $-0,14$ \\
\hline Prof. Ap.-pré & 24,00 & 11,00 & 29,00 & 13,00 & & & & \\
\hline Prof. Ap.-pós & 34,00 & 12,00 & 30,00 & 7,00 & 7,00 & $0,026^{*}$ & & \\
\hline Diferença & 6,00 & 3,00 & 1,00 & 8,00 & & & 0,39 & 0,19 \\
\hline
\end{tabular}

Notas: * $p<0,05$ nível de significância; $d=$ Média de Cohen para calcular o tamanho do efeito, sendo assim, pequeno entre 0,20 e 0,4; moderado entre 0,40 e 0,70 e grande se $d>0,70$.

Fonte: Elaboração própia.

Ao complementar a análise estatística, verifica-se o tamanho do efeito da diferença dos escores pré e pós, através da média de Cohen, conforme os parâmetros do tamanho do efeito (Espiríto-Santo \& Daniel, 2017), a avaliação do TDE II - Escrita o escore $(\mathrm{d}=0,42)$ como moderada. Porém, constata-se que o tamanho do efeito é pequeno em relação, a diferença entre os escores no TDE II - Leitura $(d=0,35)$, no CONFIAS $(d=0,32)$ e na entrevista da professora de Apoio Pedagógico $(\mathrm{d}=0,39)$, na entrevista da professora de anos iniciais $(\mathrm{d}=-0,28)$.

Na próxima tabela, apresenta-se as correlações das variáveis dependentes, sendo a correlação em que uma variável muda e a outra também é modificada. A partir dos resultados das avaliações dos testes TDE II - Escrita, TDE II - Leitura, CONFIAS e as avaliações das professoras de anos iniciais e as professoras de Apoio Pedagógico, em relação aos escores pré e pós-intervenção. A correlação de Pearson foi aplicada como procedimento para verificar a intensidade dessa interação linear, por meio da análise da correlação da significância entre os extremos (Coutinho, 2018; Creswell, 2007). Conforme os dados descritivos na Tabela 5. 
Tabela 5. Resultados da correlação entre as avaliações TDE II - Escrita, TDE II - Leitura, e entrevistas com a professora de anos iniciais e professora de apoio pedagógico

$\begin{array}{lllll}1 & 2 & 3 & 4\end{array}$

1. TDE II - Escrita 1

2. TDE II - Leitura $\quad 0,87^{* *} \quad 1$

0,00

3. Profa. Anos Iniciais

$0,62^{*}$

$0,71^{* *}$

1

0,01

0,00

4. Profa. Apoio Pedagógico

$0,68 * *$
0,00

$0,63^{*}$

$0,60^{*}$

1

5. CONFIAS

$0,55^{*}$

0,01

0,02

0,04

$0,73^{* *}$

$0,62 *$

0,01

0,29

0,30

1

Legenda: A correlação significativa no nível $p<0,05^{*}$ ou $p<0,001^{* *}$.

Fonte: Elaboração própia.

Os resultados da Tabela 6 revelam correlações positivas entre a maioria dos analisados com uma exceção, quanto a coluna do CONFIAS que não se relaciona com Profa. Apoio Pedagógico, apresentou uma correlação fraca.

Na tabela 6, verifica-se que na coluna 1 em relação ao TDE II - Escrita, constata-se correlação forte com o TDE II - Leitura $(r=0,876)$. Apresenta-se uma correlação moderada com as entrevistas da professora de séries iniciais $(r=0,627)$ e da professora de Apoio Pedagógico $(r=0,680)$, incluindo o teste CONFIAS $(r=0,552)$. A melhora nos escores dos testes é reforçada com as entrevistas das professoras. 0 grau de significância é verdadeiro, em relação à todas as correlações, em destaque para as correlações TDE II Leitura $(0,001)$, à entrevista da professora de Apoio Pedagógico (0,007), quanto ao parâmetro de significância $(p<0,05)$, sendo bem improvável que essas correlações tenham ocorrido por erro amostral (Coutinho, 2018).

Na coluna 2, em relação ao TDE II - Leitura, verifica-se uma correlação forte a com a entrevista da professora $(r=0,714)$ e o teste CONFIAS $(r=0,731)$, e uma correlação moderada com a entrevista da professora de Apoio Pedagógico $(r=0,636)$ (Coutinho, 2018). Verifica-se que a melhora nos testes é reforçada pelas observações das professoras. 0 grau de significância é verdadeiro, sendo da professora de anos iniciais ( $p=0,004)$, CONFIAS $(p=0,003)$, quanto à Professora de Apoio Pedagógico $(p=0,015)$ demonstra quanto é improvável que essas correlações tenham ocorrido de forma aleatória.

Na coluna 3, quanto à avaliação da professora de anos iniciais uma correlação moderada em relação ao Apoio Pedagógico $(r=0,602)$ e 0 teste CONFIAS $(r=0,621)$. O grau de significância é verdadeiro, em relação 
à professora de apoio pedagógico $(p=0,015)$, sendo o CONFIAS $(p=0,003)$, com possibilidades reduzidas de ter ocorrido problemas na amostragem (Coutinho, 2018).

Na coluna 4, a avaliação da professora de apoio pedagógico com o teste CONFIAS $(r=0,298)$, constata-se uma correlação fraca. 0 grau de significância é $(0,30)$, sendo assim, acima do parâmetro $(p<0,05)$, com possibilidades de ter ocorrido problemas na amostragem (Coutinho, 2018). Não foi estabelecida a correlação na medida que altera uma variável para outra ficar alterada, portanto, não apresenta uma relação entre a avaliação das professoras de apoio pedagógico com a avaliação do teste CONFIAS.

Agora, na tabela 6, trata-se do nível de evolução da escrita que se atribui uma análise qualitativa em relação ao progresso do estudante quanto ao seu processo de aprendizado (Ferreiro \& Teberosky, 1999). Ao verificar o nível de hipótese de escrita dos estudantes seguem as evoluções do processo de compreensão do sistema de escrita, antes e logo após a intervenção, o que pode ser observado na Tabela 6.

Tabela 6. Nível de escrita - pré-teste e pós-teste

\begin{tabular}{lllll} 
& & $\begin{array}{c}\text { Grupo GE } \\
\text { e GC }\end{array}$ & \multicolumn{1}{c}{$\begin{array}{c}\text { Nível de escrita - } \\
\text { pré-teste CONFIAS }\end{array}$} & \multicolumn{1}{c}{$\begin{array}{c}\text { Nível de escrita - } \\
\text { pós-teste CONFIAS }\end{array}$} \\
\cline { 2 - 5 } Estudante 1 & $3^{\circ}$ ano & GE & silábico-alfabética & alfabética \\
Estudante 2 & $3^{\circ}$ ano & GE & silábico-alfabética & alfabética \\
Estudante 3 & $4^{\circ}$ ano & GE & pré-silábica & silábico-alfabética \\
Estudante 4 & $4^{\circ}$ ano & GE & pré-silábica & silábica \\
Estudante 5 & $3^{\circ}$ ano & GE & silábico-alfabética & alfabética \\
Estudante 6 & $3^{\circ}$ ano & GE & silábico-alfabética & alfabética \\
Estudante 7 & $3^{\circ}$ ano & GC & pré-silábica & silábica \\
\hline Estudante 8 & $4^{\circ}$ ano & GC & silábica-alfabética & alfabética \\
Estudante 9 & $3^{\circ}$ ano & GC & pré-silábica & silábica \\
Estudante 10 & $3^{\circ}$ ano & GC & pré-silábica & silábica \\
Estudante 11 & $3^{\circ}$ ano & GC & silábico-alfabética & silábico-alfabética \\
Estudante 12 & $3^{\circ}$ ano & GC & alfabética & alfabética \\
Estudante 13 & $3^{\circ}$ ano & GC & silábica & silábica \\
Estudante 14 & $3^{\circ}$ ano & GC & pré-silábica & pré-silábica \\
\hline
\end{tabular}

Fonte: Elaboração própia.

Nos grupos GE e GC, nota-se nos pré-testes a hipótese de nível de escrita inicia-se no nível de escrita pré-silábica, que consiste no emprego de letras sem corresponde-las em seus valores sonoros, com pelo menos 3 letras. Essa fase, ocorre depois do primeiro nível relacionado com a diferenciação entre o desenho e a escrita, na forma de garatujas (Azenha, 1996). 
Na Tabela 6, destaca-se a hipótese de escrita silábico que consiste em utilizar uma letra para cada sílaba da palavra, sendo que as letras são reunidas de maneira aleatória, sem nenhuma correspondência com as propriedades sonoras das sílabas (Ferreiro \& Teberosky, 1999; Soares, 2016). Esta etapa promove uma transformação fundamental qualitativa na escrita infantil, mesmo sem incorporar a pauta sonora, pois contribui como um planejamento da escrita (Azenha, 1996).

O nível de escrita silábico-alfabética, quando a sílaba é analisada e representa o fonema da sílaba (Soares, 2016). Caracteriza-se pelo período de transição de uma compreensão silábica para a alfabética, contribui para evoluir para a etapa seguinte da evolução da escrita, a hipótese alfabética (Azenha, 1996).

O nível de escrita alfabética, propriamente é a incorporação da expressão sonora das grafias (Azenha, 1996), que é a hipótese da etapa final do processo de compreensão da natureza da escrita.

No GE, todos os estudantes apresentaram evolução na hipótese da compreensão na escrita. Nos testes observa-se a evolução da escrita dos estudantes, 4 estudantes estavam no nível de escrita silábica-alfabética e evoluíram para o nível de escrita alfabética. No nível de escrita pré-silábica para silábica 2 estudantes. Sendo que 1 estudante evoluiu de pré-silábica para silábica-alfabética. Nota-se que promoveu uma evolução que chegou até mesmo, superar uma etapa do nível de escrita, no período da intervenção.

No GC, do total de 7 estudantes, 4 evoluíram de hipótese de escrita, sendo 2 estudantes da hipótese pré-silábica para a silábica, 1 estudante da silábica-alfabética para alfabética. Além disso, 1 estudante já havia atingido a hipótese alfabética. Nesse sentido, constata-se que 3 estudantes permaneceram no mesmo nível de escrita pré-silábica e silábica.

Todos os estudantes envolvidos nessa pesquisa, tanto do GE quanto do GC, progrediram nas habilidades fonológicas. Alguns estudantes do GC apresentaram, nos pré-testes, resultados equivalentes aos dos pós-testes. No entanto, a pesquisa apresentou evidências que os participantes do GE tiveram um rendimento superior em relação ao GC. Tanto nas habilidades fonológicas, como na leitura e escrita.

A observação dos professores, em relação à avaliação dos estudantes quanto à intervenção com os jogos digitais no desenvolvimento da consciência fonológica, ocorreu por meio da coleta e da sistematização dos relatos. Realiza-se a análise dessas informações com a organização em categorias: $A$ - professoras que observaram o GE; B - professoras que observaram o GC. 
E as subcategorias: A1, A2, B1, B2: observou os benefícios ou não do uso dos jogos digitais no desenvolvimento da consciência fonológica processo de alfabetização (Creswell, 2007). Esses resultados são sistematizados na Tabela 7.

Tabela 7. Categorização dos relatos da percepção das professoras quanto ao uso de jogos digitais para desenvolvimento da consciência fonológica no processo de alfabetização

\begin{tabular}{|c|c|c|}
\hline Categoria & Subcategoria & Frequência \\
\hline $\begin{array}{l}\text { A. Percepção das professoras em } \\
\text { relação aos estudantes do grupo } \\
\text { experimental, que participaram da } \\
\text { pesquisa com jogos digitais no desen- }\end{array}$ & $\begin{array}{l}\text { A1. Aspectos relacionados aos benefícios } \\
\text { do emprego dos jogos digitais no des- } \\
\text { envolvimento da consciência fonológica } \\
\text { processo de alfabetização. }\end{array}$ & $28,6 \%$ \\
\hline $\begin{array}{l}\text { volvimento da consciência fonológica } \\
\text { processo de alfabetização. }\end{array}$ & $\begin{array}{l}\text { A2. Não percebe nenhuma contribuição } \\
\text { relacionada ao emprego do jogo digital no } \\
\text { rendimento dos estudantes. }\end{array}$ & $21,4 \%$ \\
\hline $\begin{array}{l}\text { B. Percepção das professoras em } \\
\text { relação aso estudantes do grupo } \\
\text { controle, que que não participaram }\end{array}$ & $\begin{array}{l}\text { B1. Aspectos relacionados ao desenvolvi- } \\
\text { mento da consciência fonológica processo } \\
\text { de alfabetização. }\end{array}$ & $25 \%$ \\
\hline $\begin{array}{l}\text { da pesquisa com jogos digitais no } \\
\text { desenvolvimento da consciência } \\
\text { fonológica processo de alfabetização. }\end{array}$ & $\begin{array}{l}\text { B2. Não percebe nenhuma contribuição } \\
\text { relacionada ao emprego ao rendimento } \\
\text { dos estudantes. }\end{array}$ & $25 \%$ \\
\hline
\end{tabular}

Fonte: Elaboração própia.

Ao comparar as entrevistas das professoras entre os GE e GC, verificou-se os progressos em relação ao aprendizado dos estudantes. As professoras do GE declararam que notaram benefícios significativos (28,6\%) em relação ao emprego dos jogos digitais para o desenvolvimento da consciência fonológica no processo de alfabetização.

No GC, as professoras notaram melhoras em torno de $25 \%$ no aprendizado dos estudantes. A professora de apoio pedagógico percebeu evolução no processo de aprendizagem dos estudantes. $E$ apenas uma professora das séries iniciais, do $4^{\circ}$ ano, percebeu avanços no processo de aprendizado de um estudante. Infere-se que o processo avaliativo ocorre quanto ao parâmetro de aprendizagem exigido em relação aos outros estudantes. Assim, não foi considerado o progresso do estudante em suas capacidades, mas o que é exigido pelo patamar estabelecido pelo currículo.

Assim, conforme os relatos notou-se que as professoras do GE consideram fundamental outra estratégia pedagógica para possibilitar 0 aprendizado dos estudantes, incluindo a adoção de diferentes estratégias que envolvam a ludicidade com os jogos digitais no contexto escolar. As professoras perceberam o interesse dos estudantes em participar da pesquisa com os jogos digitais de consciência fonológica no processo de aprendizagem do sistema de escrita alfabética. 


\section{Discussão}

Apresenta-se nesse artigo a investigação sobre o emprego dos jogos digitais para o desenvolvimento da consciência fonológica para a aprendizagem do sistema de escrita alfabética com os estudantes que apresentam desempenho abaixo do esperado. A pesquisa contribui para consolidar a fundamentação desses usos a partir de evidências (Alves \& Coutinho 2016), no sentido de compreender o processo de alfabetização por intermédio dos jogos digitais. As evidências estão fundamentadas pela natureza quase-experimental da pesquisa, com as abordagens quantitativas e qualitativas (Creswell, 2007).

Ao abordar as intervenções, com metodologia quase-experimental, com abordagem quantitativa e qualitativa, os testes estatísticos não apresentarem um desvio padrão com grande dispersão (Merriam \& Tisdell, 2016). Além disso, nos GE e GC atingiram médias aproximadas, verificou que os grupos são equivalentes. Esse resultado é fundamental por reforçar a validade do estudo.

Mesmo com uma amostragem pequena, com 14 participantes, verificou-se a ocorrência na melhora nos escores do GE em relação ao GC. 0 teste Mann-Whitney foi empregado, para testes não paramétricos para análise de um número reduzido (Dancey \& Reidy, 2019). Nesse sentido, ocorreu a comparação das amostras independentes com quantidades iguais quanto às medianas. 0 teste de leitura do TDE II apresenta no GE 9 pontos nas medianas acima do GC, apresentando a eficácia do emprego dos jogos digitais de consciência fonológica, com referência, ao processo de leitura dos estudantes. Sendo possível estabelecer uma relação com os níveis de hipótese de escrita (Ferreiro \& Teberosky, 1999), porque esses níveis não são limitantes, mas contribuem para o acompanhamento do estudante e compreender seu processo de aprendizagem que não se esgota nas avaliações (Soares, 2016).

A correlação de Pearson dos dados possibilitou verificar de que forma a intervenção com os jogos digitais influenciaram nos testes e na percepção dos professores, quanto ao rendimento dos estudantes. Constatou-se que são várias as correlações positivas entre os escores, com correlação moderada (Coutinho, 2018). Apenas a avaliação de consciência fonológica com a entrevista da professora de Apoio Pedagógico obteve uma correlação fraca. Entretanto, constatou-se a correlação efetiva das informações, tanto com a compreensão do sistema de escrita alfabética pelos estudantes, como em relação a dinâmica da intervenção com os jogos digitais que desenvolveram a consciência fonológica (Adams et al., 2006; Capovilla \& Capovilla, 2002; Lamprecht et al., 2009). 
Essa correlação reforça aspectos avaliados pelas professoras, quanto a apropriação dos estudantes em relação ao sistema de escrita alfabética, no reconhecimento de letras e das palavras (Morais, 2013; Scliar-Cabral, 2013; Soares, 2016). Em relação consciência fonológica e sua relação processo de alfabetização, obteve-se a melhora das habilidades dos estudantes em identificar as rimas, aliterações, associar a sílaba com o som, quanto a relação entre grafema e fonema (Adams et al., 2006; Capovilla \& Capovilla, 2002; Lamprecht, 2009; Maluf \& Barrera, 1997; Moojen, 2011).

Ao complementar a discussão, verificou-se a comparação do progresso no nível de escrita a partir da avaliação do CONFIAS (Moojen, 2011), dos estudantes antes e após as intervenções. A maioria dos estudantes do GE avançaram nos níveis de escrita (Adams et al., 2006; Capovilla \& Capovilla, 2002; Lamprecht, 2009; Maluf \& Barrera, 1997; Moojen, 2011; Pinheiro, 1994). Porém, um estudante não apresentou avanços no GE. No GC três estudantes se mantiveram no mesmo nível de escrita.

No processo de aprendizagem, os estudantes entenderam o jogo durante as intervenções. Nota-se que jogaram com autonomia, avançavam as etapas do jogo e venceram progressivamente os desafios. Ao observar o avanço das etapas e a autonomia dos estudantes com os jogos digitais, ocorre a promoção da inclusão digital por meio do uso das TIC, na utilização dos aplicativos e dos jogos digitais em desktop (Ramos et al., 2018). Que inclusive a inclusão digital contribuiu o processo de aprendizagem desses estudantes, favoreceu a compreensão do processo do sistema de escrita alfabética com o desenvolvimento da consciência fonológica (Adams et al., 2006; Lamprecht, 2009; Ramos et al., 2018).

Evidencia-se que os jogos foram apresentados conforme os níveis de complexidade que possibilita uma sequência de aprendizado dos estudantes (Ramos \& Cruz, 2018). Os jogos trabalhavam com uma sequência em relação do reconhecimento dos fonemas em relação aos grafemas (Adams et al., 2006; Lamprecht, 2009).

A observação como participante durante a sessões, contribuiu para verificar, através de um viés subjetivo, constatar o interesse dos estudantes pelos jogos digitais, e o potencial desses recursos para o aprendizado desses sujeitos, que foi relatado também por uma das professoras. Ao observar 0 processo de aprendizagem dos estudantes, confirmou por evidências que o uso do jogo digital de forma lúdica e divertida, possibilitou a fixação da aprendizagem, por meio da interação e a repetição (Ramos \& Cruz, 2018, p. 25). Essas ações que contribuíram para o processo de compreensão do sistema de escrita alfabética (Dehaene, 2012; Wolf, 2019). 


\section{Considerações finais}

$O$ artigo pretendeu apresentar por meio de evidências que o emprego dos jogos digitais contribuiu para o processo de alfabetização. A relevância dessa temática demanda o desenvolvimento de mais pesquisas sobre jogos digitais.

De modo geral, o estudo verificou que os estudantes tiveram uma evolução em relação ao seu aprendizado, por meio do emprego das TIC, através do uso dos jogos digitais para desenvolver a consciência fonológica no processo de alfabetização. Mas verifica-se a demanda por dar continuidade nesse processo, em relação a todos os estudantes que participaram da intervenção, porque a aprendizagem não se esgota na pesquisa. Por isso, é essencial o compartilhamento desses estudos, para que professores consigam ter acesso a esse conhecimento e utilizá-lo no cotidiano da escola. Ao considerar o lúdico no processo de aprendizagem, despertar o interesse das crianças e jovens. Assim, proporcionar uma experiência no contexto escolar mais significativa, a partir do momento em que os estudantes se sintam mais incluídos em seu processo de aprendizagem no contexto escolar.

A limitação dos estudos foi referente à quantidade de participantes e o tempo de intervenção de 12 horas. Devido ao desafio de conciliar os tempos da escola, em relação aos horários de aula e o tempo da pesquisa, quanto aos espaços disponíveis no âmbito escolar para realizar as intervenções.

Em relação às pesquisas futuras além da investigação da etapa inicial do processo de alfabetização, é necessário ampliar os estudos quanto às etapas posteriores que não se encerra por ser um processo continuum. No sentido de contribuir na leitura proficiente, que envolve outras habilidades no decorrer do aprendizado dos estudantes. No entanto, vale ressaltar a demanda em aumentar o tempo de intervenção no campo de estudo, para envolver mais participantes, em diversas etapas de aprendizado na pesquisa para ampliar as possibilidades quanto as evidências no uso dos jogos digitais no processo de alfabetização.

\section{Referências}

Adams, M.J., Foorman, B.R., Lundberg, I. \& Beeler, T.R.C. (2006). Consciência fonológica em crianças pequenas. Porto Alegre: Artmed.

Alves, L. \& Coutinho, I. de J. (Orgs.). (2016). Jogos Digitais e aprendizagem: Fundamentos para uma prática baseada em evidências. Campinas: Papirus. 
Azenha, M.G. (1996). Imagens e letras: os possíveis acordos de Ferreiro e Luria. São Paulo: Ática.

Batista, A.A.G., Silva C.S.R., Bregunci, M.G., Castanheira M.L. \& Monteiro. S.M. (2012). Alfabetização e letramento: questões sobre avaliação. En Secretaria de Educação Básica. Pró-Letramento: Programa de formação continuada de professores dos anos/ séries iniciais do ensino fundamental: alfabetização e linguagem. (pp. 1-50) (2). Brasília: Ministério da Educação, Secretaria de Educação Básica.

Bentzen, W.R. (2013). Guia para observação e registro do comportamento infantil. São Paulo: Cengage Learning.

Boler, S. \& Kapp, K. (2018). Jogar para aprender: tudo o que você precisa saber sobre o design de jogos de aprendizagens eficazes. São Paulo: DVS.

Capovilla, F.C. \& Capovilla, A.G.S. (2002). Problemas de Aquisição de Leitura e Escrita: Efeitos de Déficit de Discriminação Fonológica, Velocidade de Processamento e Memória Fonológica. Estudos e Pesquisas em Psicologia, 2 (1), 26-50. Recuperado de https://bit.ly/3rU9uys.

Coutinho, C.P. (2018) Metodologia de investigação em ciências sociais e humanas: teoria e prática. Almedina.

Creswell, J.W. (2007). Projeto de Pesquisa: Métodos, qualitativo, quantitativo e misto. Artmed.

Dancey, C.P. \& Reidy, J. (2019). Variáveis e delineamento de pesquisa. En C. P. Dancey \& J. Reidy Estatística sem matemática para psicologia (pp. 1-23). Porto Alegre:Penso.

Dehaene, S. (2012). Os neurônios da Leitura: como a ciência explica nossa capacidade de ler. Porto Alegre: Penso.

Espírito-Santo, H. \& Daniel, F. (2017). Calcular e Apresentar Tamanhos do Efeito em Trabalhos Científicos: as Limitações do $\mathrm{P}<0,05$ na Análise de Diferenças de Médias de dois grupos. Revista Portuguesa de Investigação Comportamental e Social, 1(1), 3-16. Recuperado de http://bit.ly/3ni3753

Ferreiro, E. \& Teberosky, A. (1999). A evolução da escrita. En E. Ferreiro \& A. Teberosky Psicogênese da língua escrita (pp.191-257). Artmed.

Gil, A.C. (2002). Como elaborar projetos de pesquisa. São Paulo: Atlas.

Instituto Paulo Montenegro (2018). Indicador de analfabetismo funcional - INAF: Estudo especial sobre analfabetismo e mundo do trabalho. São Paulo: Instituto Paulo Montenegro. https://bit.ly/2XeZthy

Jamshidifarsani, H., Garbaya, S., Lim, T., Blazevic P. \& Ritchie, J. M. (2019). Technology-based reading intervention programs for elementary grades: An analytical review. Computers \& Education, 128, 427-451. https://doi.org/10.1016/j.compedu.2018.10.003.

Kulju, P. \& Mäkinen, M. (2019). Phonological strategies and peer scaffolding in digital literacy game-playing sessions in a Finnish pre-primary class. Journal of Early Childhood Literacy, 1-23. https://doi.org/10.1177/1468798419838576

Lamprecht, R.R. (Org.) (2009). Consciência dos Sons da Língua: Subsídios teóricos e práticos para alfabetizadores, fonoaudiólogos e professores de língua inglesa. Porto Alegre: Edipucrs.

Lüdke, M. \& André, M.E.D. (1986). Métodos de coleta de dados: observação, entrevista e análise documental. En M. Lüdke \& M. E. D. André. Pesquisa em educação: abordagens qualitativas (pp. 25-44). São Paulo: Epu. 
Maluf, M.R. \& Barrera, S.D. (1997). Consciência fonológica e linguagem escrita em pré-escolares. Psicologia: Reflexão e Crítica, 10(1), 125-145. Recuperado de http://bit.ly/3rP5cZP

Mcgonigal, J. (2012). A realidade em jogo. Rio de Janeiro: Bestseller.

Merriam, S.B. \& Tisdell, E.J. (2016). Dealing with validity, reliability, and ethics. En S. B. Merriam \& E. J. Tisdell. Qualitative research: a guide to design and implementation. A guide to design and implementation. (pp. 237-266). Hoboken:Jossey-Bass.

Moojen, S. (Coord.) (2011). CONFIAS: Consciência Fonológica: Instrumento de Avaliação Sequencial. São Paulo: Casa do Psicólogo.

Morais, J. (2013). Criar leitores: Para professores e educadores. Barueri: Manole.

Pérez-Gómes, Á.I. (2015). Educação na era digital: a escola educativa. Porto Alegre: Ed. Penso.

Pinheiro, Â.M.V. (1994) Leitura e escrita: Uma Abordagem Cognitiva. Campinas: Editorial Psy.

Ramos, D., \& Cruz, D.M. (2018). Jogos digitais e educação: uma história de implicação e desejo. En D. K. Ramos, \& D. M. Cruz (Orgs.). Jogos digitais em contextos educacionais (pp. 21-46). Curitiba: Editora CRV.

Ramos, D., de Melo, H. \& Mattar, J. (2018). Jogos digitais na escola e inclusão digital: intervenções para o aprimoramento da atenção e das condições de aprendizagem. Revista Diálogo Educacional, 18(58), 670-692. http://doi.org/10.7213/1981-416X.18.058.DS04

Richardson, U. \& Lyytinen, H. (2014). The GraphoGame Method: The Theoretical and Methodological Background of the Technology-Enhanced Learning Environment for Learning to Read. Human Technology, 10(1), 39-60, http://doi.org/10.17011/ht/ urn.201405281859

Ronimus, M., Kujala, J., Tolvanen, A., Lyytinen, H. (2014). Children's engagement during digital game-based learning of reading: The effects of time, rewards, and challenge. Computers \& Education, 71, 237-246. https://doi.org/10.1016/j.compedu.2013.10.008

Rosas, R., Escobar, J. P., Ramírez, M. P., Meneses, A. \& Guajardo, A. (2017). Impact of a computer-based intervention in Chilean children at risk of manifesting reading difficulties / Impacto de una intervención basada en ordenador en niños chilenos con riesgo de manifestar dificultades lectoras. Infancia y Aprendizaje, 40(1), 158188. http://doi.org/10.1080/02103702.2016.1263451

Salen, K. \& Zimmerman, E. (2012). Regras do jogo: principais conceitos. São Paulo: Blucher.

Scliar-Cabral, L. (2013). Sistema Scliar de Alfabetização: Fundamentos. Florianópolis: Lili.

Soares, M. (2017). Alfabetização e letramento. São Paulo: Contexto.

Soares, M. (2016). Alfabetização: a questão dos métodos. São Paulo: Contexto.

Stein, L. M. (2014). TDE: teste de desempenho escolar: manual aplicação e interpretação. São Paulo: Pearson Clinical Brasil.

Wolf, M. (2019). O cérebro no mundo digital: os desafios da leitura na nossa era. São Paulo: Contexto. 